\title{
Intense Benthic Grazing on Phytoplankton in Coral Reefs Revealed Using the Control Volume Approach
}

\author{
Amatzia Genin, Gitai Yahel \\ The Hebrew University. Eilat, Israel
}

\author{
Matthew A. Reidenbach, Stephen G. Monismith and Jeffrey R. Koseff \\ Stanford University. Stanford, California USA
}

\begin{abstract}
A major objective of biogeochemical studies of coral reefs is to quantify fluxes of particulate and dissolved matter between the reef and overlying waters. However, direct measurements of these fluxes are hard to obtain due to the typically small concentration changes as the water flows over the bottom and due to shear, turbulent mixing and concentration gradients characterizing benthic boundary layers. Using state-of-the-art underwater technology, we were able to apply the "Control Volume" approach to measure in situ phytoplankton grazing on a scale of a whole coralreef community. The results indicate that the import of carbon and nutrients via this grazing is a major, previously underestimated, trophic pathway in coral reefs. The amount of phytoplankton grazed by $1 \mathrm{~m}^{2}$ of reef is similar to the total phytoplankton produced in the entire water column of the surrounding sea under $1 \mathrm{~m}^{2}$ of sea-surface. The import of allochthonous nutrients into the reef via this grazing balances the downstream leak of dissolved nutrients. Physically, the flow over the rough topography of the reef produces enhanced turbulence, enabling high grazing rates to be sustained, while on larger scales, the exchange between the offshore ocean and the reef is supported by buoyancy-driven flows. With the advent of underwater technology, the control volume technique is no longer limited to unique situations (e.g. closed lagoons, shallow flats), but should be generally applicable for measurements of benthicpelagic fluxes in oceans and lakes.
\end{abstract}

\section{Introduction}

The answers to many key ecological questions in benthic ecology depend on accurate measurements of fluxes across the benthic boundary. The coral reef is one of many benthic ecosystems for which such measurements are scarce (reviewed by Hatcher, 1997). Available estimates are questionable since they either represent unique situations (e.g. mixed waters over a shallow flat), or are based on indirect measurements (e.g. extrapolation from chambers, laboratory flumes). We are still unsure, for example, whether coral reefs are a net sink or source for atmospheric $\mathrm{CO}_{2}$ (e.g. Kayanne et al., 1995 vs. Gattuso et al., 1996), nor is it clear to what extent nutrients in coral reefs are recycled (Odum, 1971), absorbed directly from the flowing water (Atkinson, 1992), or imported via intense benthic grazing on plankton (Glynn, 1973; Fabricius and Dommisse, 2000). Even the measure of carbon input via community grazing on plankton is imprecisely estimated for coral reefs, except for a few unique situations such as closed lagoons or perforated reefs (Hatcher, 1997; Yahel et al., 1998). Nevertheless, it is generally agreed that the gross productivity of coral reefs, rivaling that of the most productive ecosystems in the ocean, is an order of magnitude higher than that of the typically poor, oligotrophic sea around the reef.
Obviously, nutrient scarcity, that limits the phytoplankton productivity in the ambient waters, is somehow relaxed in coral reefs. Earlier investigators (e.g. Odum, 1971) considered tight recycling within the reef community to be the main mechanism allowing high gross productivity to be maintained. This old paradigm has recently shifted,due in great part to the studies of Atkinson and colleagues (e.g. Atkinson, 1992; Hearn et al., 2001). Their work showed that direct removal of dissolved nutrients by the reef community, a process that depends on flow and bottom drag, is sufficiently high to account for the ecosystem's productivity, specifically at sites where the bottom is rough and the currents are strong. However, neither the "recycling" nor the "nutrient uptake" explanations account for the leak of nutrients from the ecosystem to the open sea, which can be substantial (e.g. Delesalle et al., 1998; Hata et al., 1998). "Exotic" sources of nutrients, such as groundwater and upwelling, were found at some sites (e.g. D'Elia et al., 1981) but their general prevalence is questionable (Tribble et al., 1994).

Clearly, accurate measurements of mass fluxes across the bottom-water interface are required in order to understand the trophic functioning of coral reefs (as well as many other benthic ecosystems). However, such 
in situ measurements are almost always difficult to obtain since gradual changes of concentrations in the water flowing over the bottom are usually hard to detect, while at the same time, those concentrations may change considerably with distance from the bottom (e.g. O'Riordan et al., 1993; Yahel et al., 1998). Generally, mass fluxes between stationary objects and moving fluids can be straightforwardly measured under conditions of fairly homogeneous or confined flow. Common examples include studies conducted in flumes and wind tunnels, to more complex measurements made in streams and rivers (Street et al., 1996). Various techniques (reviewed by Wildish and Kristmanson, 1997) have been used to overcome the difficulties in measuring mass fluxes in such habitats. One such technique is the "chamber" experiment, where a single organism or a small section of the benthic community is enclosed in situ in a water-tight container (e.g. Hopkinson et al., 1991). However, this highly intrusive method is size-limited, blocks natural flows, prevents food replenishment and potentially introduces serious artifacts. Other techniques can be applied in unique situations where the geometry is advantageous, such as lagoons and channels. In yet another technique, Eulerian measurements at one spot (e.g. Atkinson, 1992) or Lagrangian measurements aboard a raft (e.g. Barnes and Lazar, 1993) are made at a place where the water column is assumed to be fully mixed - e.g. the reef flat. However, in many cased such measurements are made in situations where the flow is vertically sheared and the water is not well mixed, so that calculations of mass fluxes that are based on measuring the gradual changes in the concentration of elements at a fixed depth as the water flows down-stream (e.g. Fabricius and Dommisse, 2000) could be erroneous.

\section{The Control Volume Experiment}

The artifacts, restrictions and assumptions underlying the above techniques render them non-usable in most benthic habitats, particularly the wide-open, subsurface parts of ecosystems, such as the coral reef slope (Hatcher, 1997). Here we introduce a novel application of a standard, well-established engineering approach, the "Control Volume" (Street et al., 1996), to measure in situ biogeochemical fluxes over large sections of coral reefs. Underlying this approach is the designation of an imaginary box (Figure 1) in which the base is a section of the benthic community and the four "virtual walls" extend through the water column up to either a clear boundary (e.g. sea surface) or an imaginary "ceiling". By calculating net fluxes through the walls and ceiling one can determine (through integration) the net sink (or source) of a substance at the volume's "floor", i.e. across the benthic-water interface. Fluxes are calculated based on simultaneous measurements of currents and concentrations across the volume.

Our objective was to evaluate the extent to which allochthonous carbon and nutrients are imported to the reef via benthic grazing on water-born plankton.

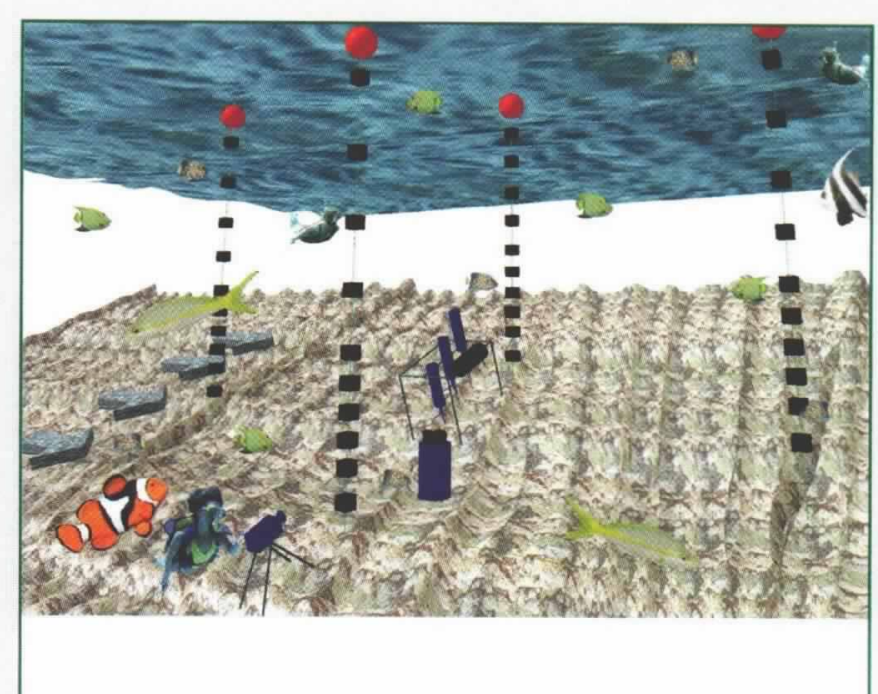

Figure 1. A schematic drawing of the Control Volume (approximately $20 \mathrm{~m} \times 10 \mathrm{~m}$ ) at the coral reef. Black squares indicate the pumps, 10 on each of four mooring lines, with the bottom-most pump at $20 \mathrm{~cm}$ above bottom and the uppermost at $1 \mathrm{~m}$ below the surface (see Photo 3). Sub-surface floats (red, top) were used to keep the moorings taut. Forty PVC pipes, each $100 \mathrm{~m}$ long and $12 \mathrm{~mm}$ in diameter, were used to run the water from each pump to the shore (see Photo 4). The blue instruments at the center of the "box" represent the 3 ADVs (on a tripod) and an uplooking ADCP (on the bottom) (see Photo 5). A video camera (blue, front) was used to assure the absence of divers during the runs and that the instruments' position and orientation remained unchanged. Wide arrows on the left indicate flow direction.

Rich populations of benthic phytoplankton feeders, including sponges, tunicates, bivalves, bryozoans and polychaetes, are ubiquitous in all coral reefs, both on the bottom (Photo 1; Yahel et al., 1998) and in numerous cryptic crevices within the substrate (Richter et al., 2001). Our working hypothesis was that the feeding rate by this guild of benthic grazers was sufficiently high so that the amount of nutrients imported to the benthic community, in the grazed phytoplankton alone, could balance the leak of dissolved nutrients from the studied reef (measured by Korpal, 1991). Furthermore, we hypothesized that the flux of phytoplankton biomass to the benthic community should be supported by turbulent mixing which serves to renew depleted waters near the bottom and to enhance mass transfer over the rough topography of this ecosystem (Thomas and Atkinson, 1997). Accordingly, our control volume experiment was designed to simultaneously measure the rate of phytoplankton grazing by the coral reef community and the governing hydrodynamic characteristics of the reef.

The work was carried out in summer 1999 on the open, fore-reef slope in front of the $\mathrm{H}$. Steinitz Marine Biology Laboratory in Eilat, Israel (Figure 2; Photo 2). A 


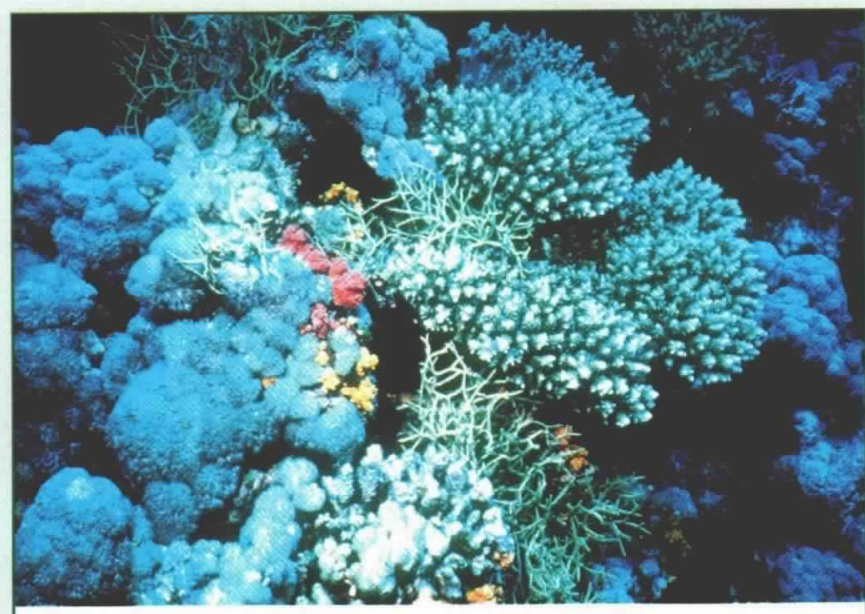

Photo 1. A picture of a rich coral reef in the Red Sea, showing the high diversity of corals and invertebrates.

diverse reef community covered about a third of the rocky bottom, where upright corals and knolls created a typical bottom relief of the order of $0.5 \mathrm{~m}$ (Photo 3). The reef is exposed to moderate currents and the surface waves are almost always small. The open sea is oligotrophic, primarily during summer, with integrated water-column productivity of $0.05-0.2 \mathrm{~g} \mathrm{C} \mathrm{m}^{-2} \mathrm{~d}^{-1}$ (Reiss and Hottinger, 1984), while the productivity at the reef is 10-20 times higher (Barnes \& Lazar, 1993).

Since the distribution of plankton is notoriously patchy, we instrumented the coral reef using an array of densely-spaced samplers. Replicated samples were

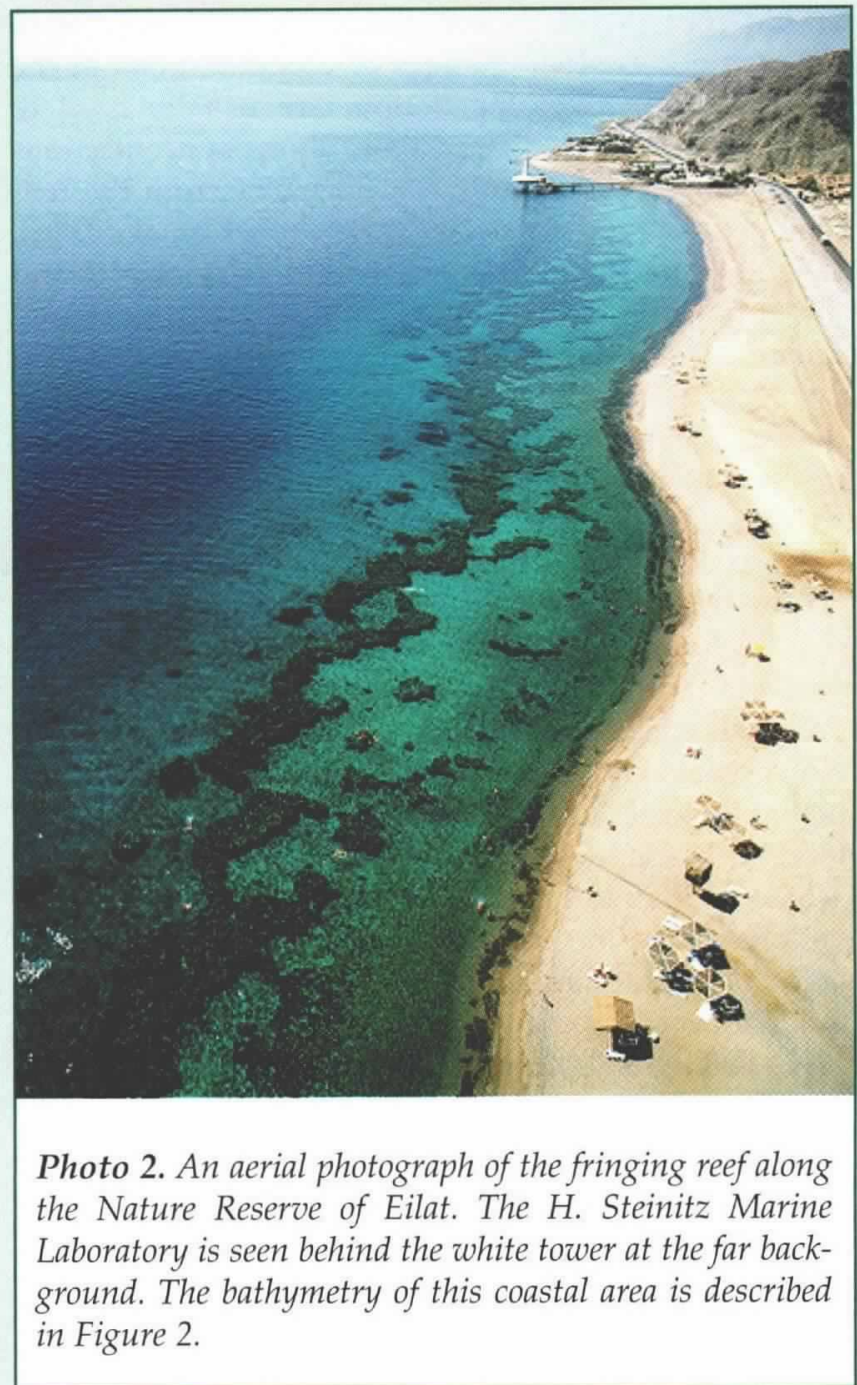

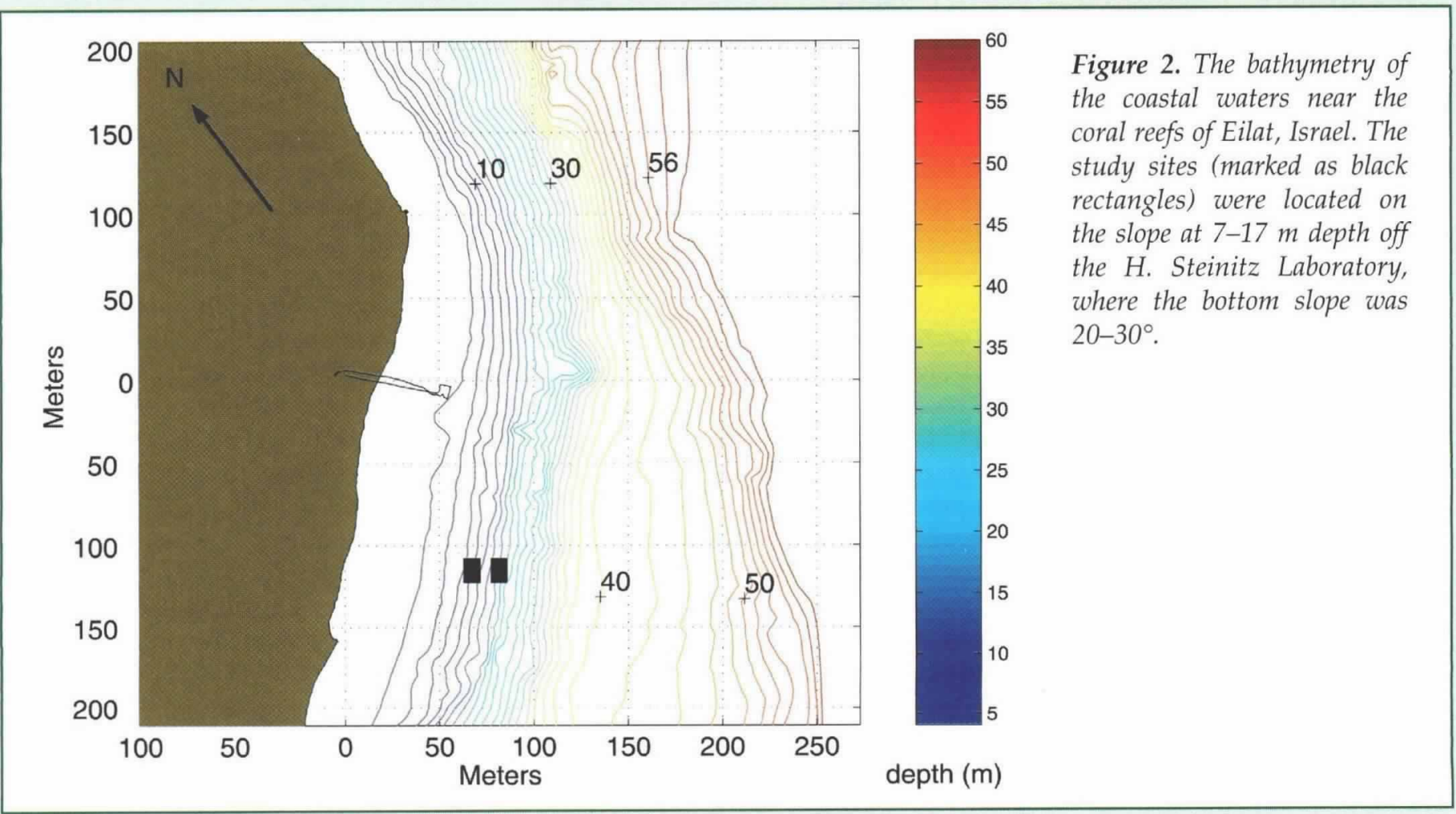




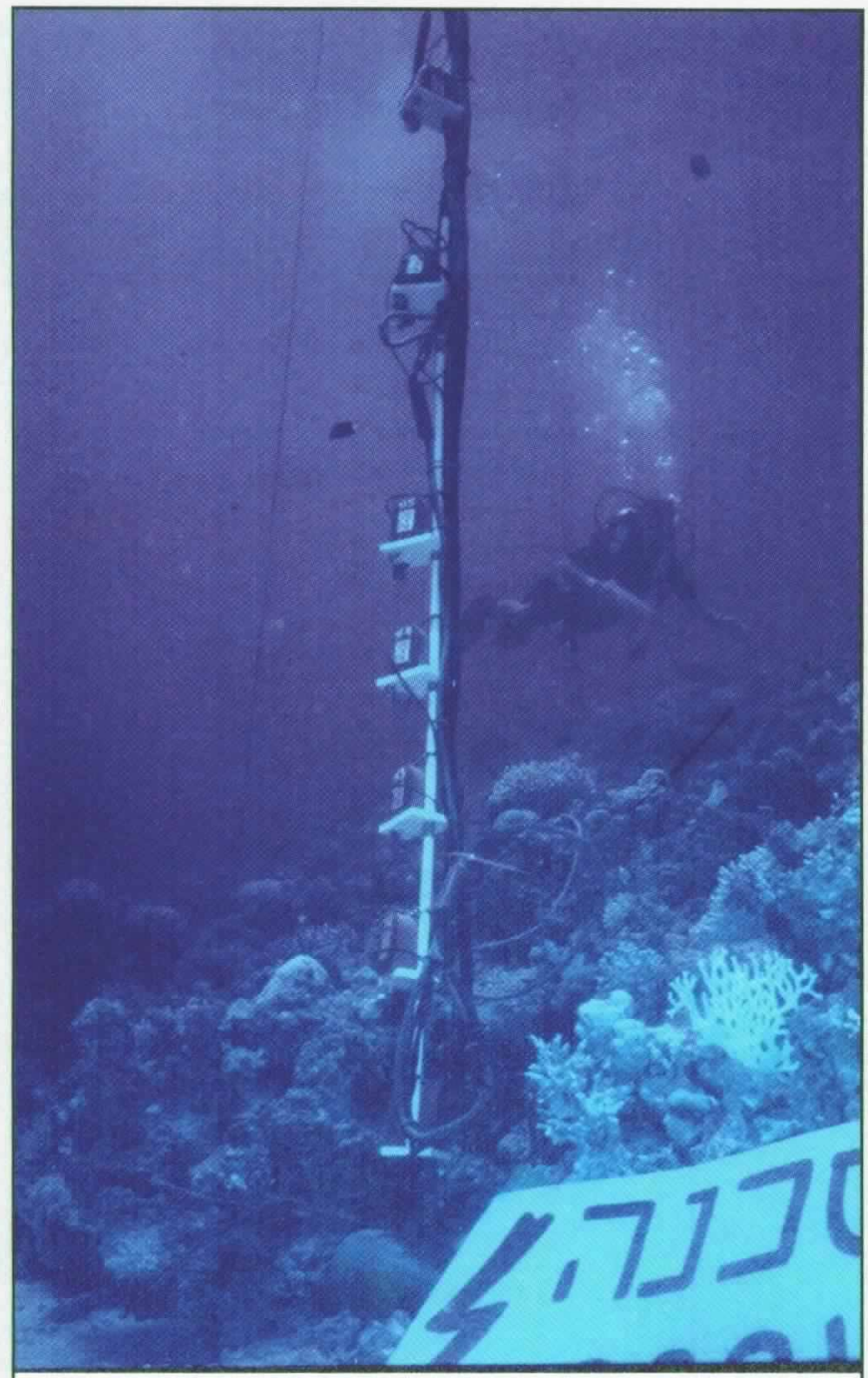

Photo 3. One of the four pump arrays deployed at the corners of the Control Volume over the coral reef in Eilat. The pumps delivered the water to the shore via the pipes seen along the mooring line.

simultaneously obtained from 40 different points in the control volume using submerged pumps (Photos 3,4), while currents and hydrodynamic parameters were measured with 5 different current meters (Photo 5), covering the entire water column. A control experiment was performed at one of the sites by covering the reef with a contour-fitting nylon sheet so that the benthic community was physically separated from the overlying waters (Photo 6). Figure 3 is an example of the measurements obtained in a single run, showing the typical current and chlorophyll profiles in the coral reef and the up-down stream difference in chlorophyll concentration.

The overall average grazing rate at the reef (calculated from 60 separate experiments) was $0.3 \mathrm{~g} \mathrm{C} \mathrm{m}^{-2} \mathrm{~d}^{-1}$, similar to the entire phytoplankton productivity in the adjacent open sea. No significant grazing was

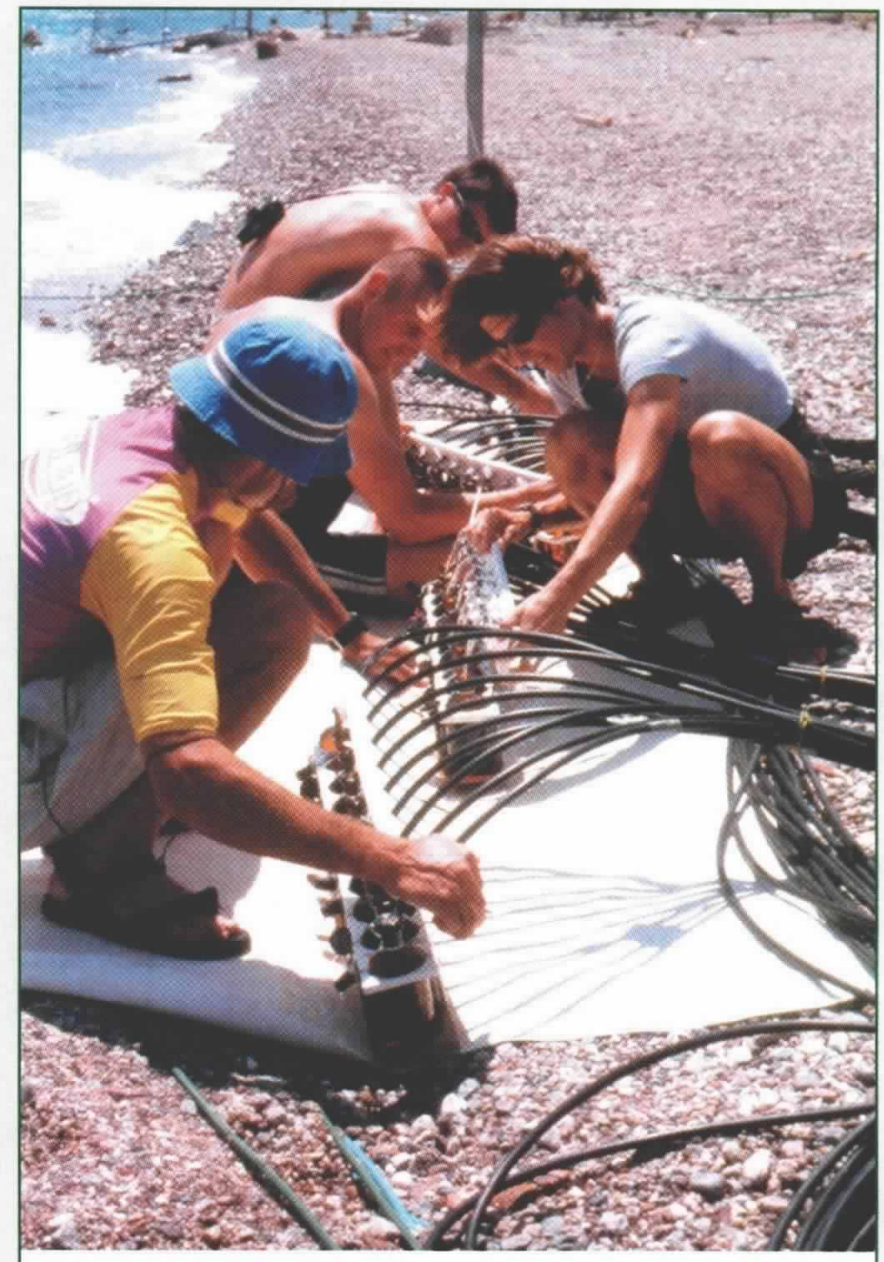

Photo 4. Sampling the pumped water on the shore. Four persons sampled the water simultaneously from all 40 pumps.

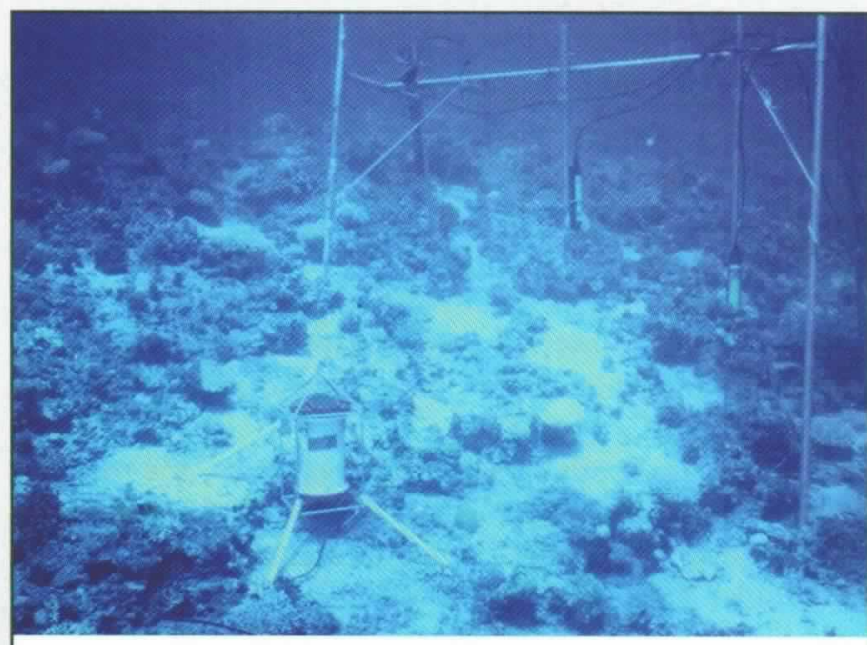

Photo 5. The tripod with the three down-looking Acoustic Doppler Velocimeters (background) and the bottommounted, up-looking Acoustic Doppler Current Profiler (foreground). 
observed when the reef was covered with the sheet of nylon (the "null" experiment, see Photo 6). Based on the local C:N ratio, the observed grazing rate accounted for over $90 \%$ of the leakage of nitrogen-nutrients from this reef (Korpal, 1991). Rates of phytoplankton grazing are frequently expressed using the surrogate term "clearance rate": the volume of ambient sea water $\left(\mathrm{m}^{3}\right)$ that contains a quantity (gr) of phytoplankton equal to the total amount removed by the benthic community. Our measurements indicated that $1 \mathrm{~m}^{2}$ of coral reef "cleared" about $25 \mathrm{~m}^{3}$ of water per day, more than the dense beds of mussels in the St. Lawrence Estuary (Fréchette et al., 1989) and 3-4 times higher than typical clearance rates estimated for bivalve beds in San Francisco Bay (Cloern, 1982; Cole et al., 1992). Given that velocities over many benthic habitats such as the San Francisco Bay are much larger than what we observe over the Eilat reef, how can the reef community sustain such high fluxes to the bed? The most likely explanation is the unusual topographic roughness of coral reefs that greatly enhances turbulence and mixing within the benthic boundary layer ( $\mathrm{O}^{\prime}$ Riordan et al., 1993; Thomas and Atkinson, 1997). Is roughness the sole explanation?

From the standpoint of mass transfer, the bottom roughness can be characterized by the drag coefficient $C_{D}$, i.e., the proportionality between bottom stress and the square of the current speed. Using our near-bottom current measurements to calculate $C_{D}$, we found that $C_{D} \approx 0.01$. This value is about four times higher than the canonical value typically found over flat bottoms (Gross and Nowell, 1983), although not at large as values suggested by others which can be as high as 0.1 (e.g. Hearn, 1999). However, while reef roughness enhances vertical exchange, turbulent mixing by itself cannot maintain high fluxes to the bed. Particularly in a system such as a long fringing reef where the current is predominantly along the reef (Figure 4a), a progressive depletion of food should have been found far downstream. Our observations indicated that on a large scale $(\mathrm{km})$ no such gradient occurred, either in phytoplankton or their benthic grazers. Thus, an additional mechanism must replenish waters over the reef by transporting phytoplankton-rich waters from the open sea (Yahel et al., 1998) onto the reef. Such a mechanism would allow the reef community to maintain high grazing rates over large temporal and spatial scales.

In the gradually sloping Red Sea reefs, the mechanism is a thermal flow, driven by differential heating and cooling of the shallow water column over a slope, much like the pattern observed in lakes (Monismith et al., 1990; Farrow and Patterson, 1993). During the day, inshore waters, because they are shallower, become warmer than those offshore, driving a surface outflow. At night, surface cooling causes the inshore regions to become colder and flow down the slope out into the stratified waters offshore. Our ADCP records clearly show this pattern (Figure 4b). The cross-shore flows,

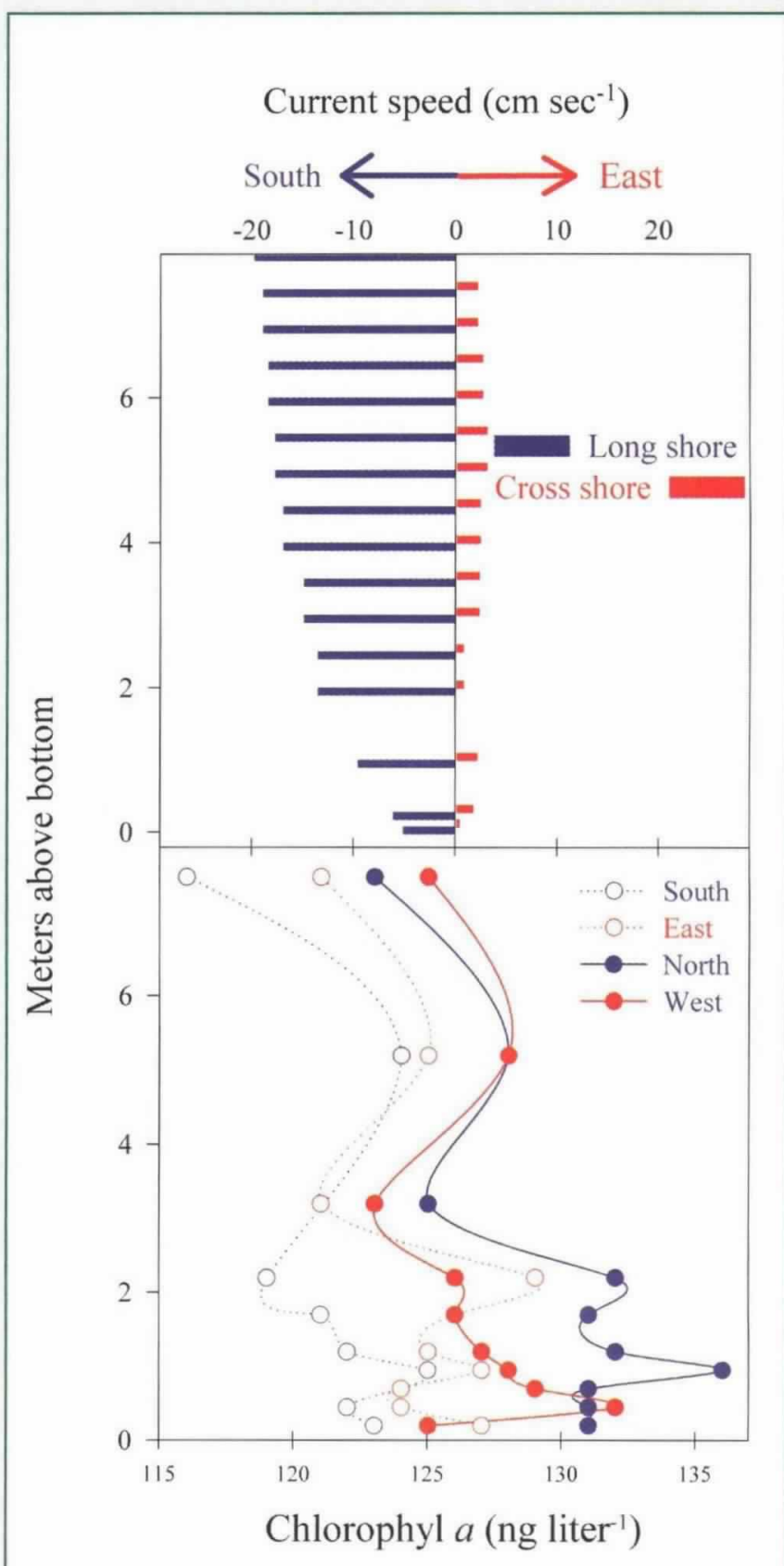

Figure 3. Profiles of currents (top) and concentration of chlorophyll a (mid, bottom) during a single run of the control volume experiment (4 September, 1999, 08:57 local time). In the top panel, positive values of the longshore (blue) and cross-shore (red) currents indicate current directions to the north and east, respectively. Thus, during the time of this control volume measurement the current direction was mostly along the reef to the south with a weaker cross-reef component to the east. Note the general correspondence between the flow direction and a decline in chlorophyll concentration downstream. Patchiness of phytoplankton and spatial non-uniformity in the flow sometime disrupt such correspondence, so that the measurements must be repeated many times. 
although much weaker than the predominant longshore currents (Figure 4a), play a special role in maintaining the overall flux of phytoplankton biomass to the reef from offshore. The operation of such a thermal flow over coral reefs was first suggested by Boden (1952), who observed that the lagoon defined by Bermuda and its system of reefs was $0.2^{\circ} \mathrm{C}$ warmer than the nearby oceanic waters.

\section{Conclusions}

Our study provides the first direct measurements of plankton grazing by a benthic community over a deep open slope with a vertically sheared benthic boundary layer. The application of a physical-biological Control Volume with the use of a diverse array of advanced instrumentation, showed that phytoplankton grazing, a previously underestimated factor in coral reefs, constitutes a major source of carbon and nutrients to the reef community at our Red Sea site. Furthermore, the high topographic roughness, an ubiquitous characteristic of all coral reefs, plays a key role in enhancing

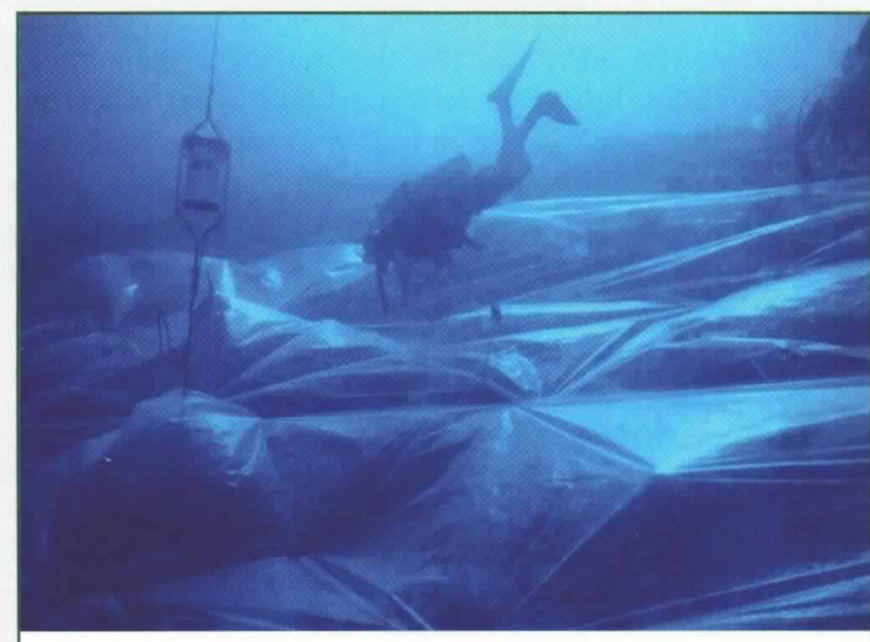

Photo 6. The control experiment: The coral reef was covered with a wide plastic sheet to separate benthic animals from the overlying water.

\section{(a)}
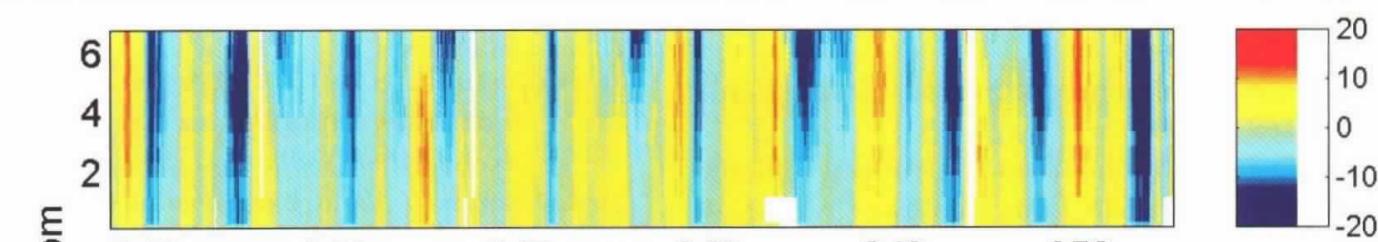

(b)

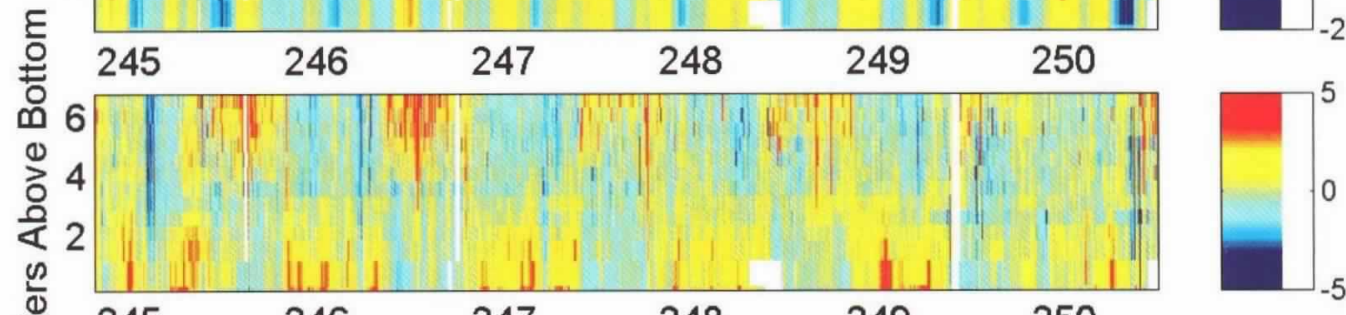

(c)

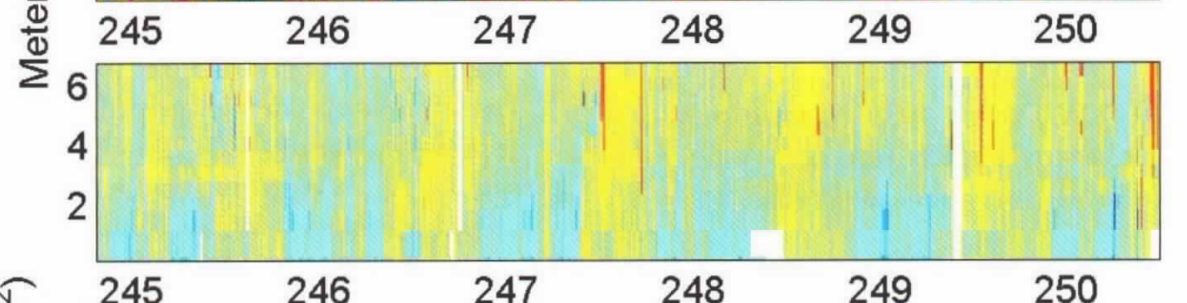

(d)
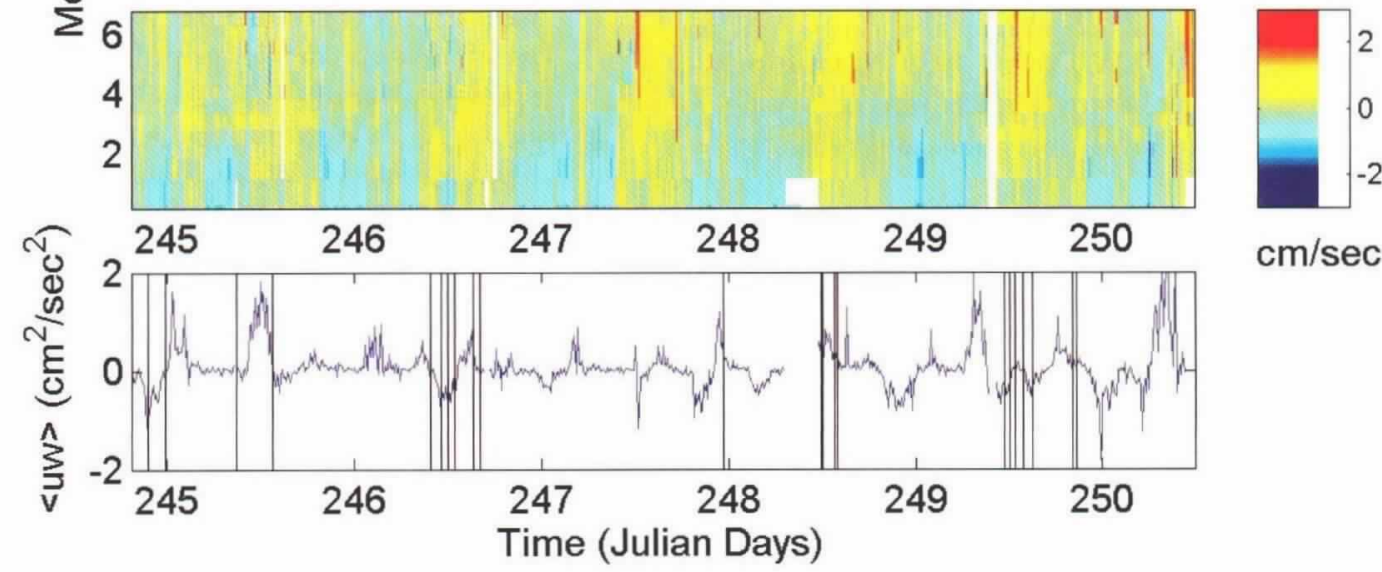

$\mathrm{cm} / \mathrm{sec}$

Figure 4. Velocities $\left(\mathrm{cm} \mathrm{s}^{-1} ; a-c\right)$ and Reynolds Stresses $\left(\mathrm{cm}^{2} \mathrm{~s}^{-2} ; d\right)$ during the Control Volume Experiment at the shallower site (2-7 September, 1999). The three velocity panels describe the vectors in the directions $\boldsymbol{a}$ ) parallel to the reef, $\boldsymbol{b}$ ) perpendicular to the reef and c) vertical, with positive values indicating northward, eastward and upward flow, respectively. For better visualization, different color scales were used for each component. Note the strong semi-diurnal pattern in the long-shore, and the diurnal pattern in the cross-shore and vertical components. Vertical lines in d) indicate the times of control volume measurements. 
turbulence, hence replenishing depleted waters near the bottom. In addition, the thermal cycling, a phenomenon generally expected in a shallow system with sloping bottom, plays a major role in replenishing the water over the whole reef, allowing high grazing rates to be maintained. Finally, because of its fundamental, basic nature, the classical Control Volume approach should be generally applicable for most benthic habitats, from the subtidal zone to the abyss.

\section{Acknowledgements}

This study was supported by the US-Israel Binational Science Foundation and the Stanford University Bio-X Interdisciplinary Research Initiative. We thank G. Weil for drawing Figure 1, D. Fong for assistance with the bathymetric chart, and M. Ohevia, I. Ayalon, R. Holzman, R. Yahel, R. Motro, S. Ekstein, S. Nielsen, E. Dunkelberger, Y. Shif, and A. Brandes for their help with the field work.

\section{References}

Atkinson, M.J., 1992: Productivity of Enewetak Atoll reef flats predicted from mass transfer relationships. Cont. Shelf. Res., 12, 799-807.

Barnes D.J. and B. Lazar, 1993: Metabolic performance of a shallow reef patch near Eilat on the Red Sea. J. Exp. Mar. Biol. Ecol., 174,1-13.

Boden B.P., 1952: Natural conservation of insular plankton. Nature, 169, 697-699.

Cloern, J.E., 1982: Does the benthos control phytoplankton biomass in South San Francisco Bay? Mar. Ecol. Progr. Ser., 9, 191-202.

Cole, B.E., J.K. Thompson and J.E. Cloern, 1992: Measurement of filtration rates by infaunal bivalves in a recirculating flume. Mar. Biol., 113, 219-225.

Delesalle B, R. Buscail, J. Carbonne, T. Courp, V. Dufour, S. Heussner, A. Monaco and M. Schrimm, 1998: Direct measurements of carbon and carbonate export from a coral reef ecosystem (Moorea Island, French Polynesia). Coral Reefs, 17, 121-132.

D'Elia, C.F., K.L. Webb and J.W. Porter, 1981: Nitrate-rich groundwater inputs to Discovery Bay Jamaica: A significant source of $\mathrm{N}$ to local coral reefs. Bull. Mar. Sci., 31, 903-910.

Fabricius, K.E. and M. Dommisse, 2000: Depletion of suspended particulate matter over coastal reef communities dominated by zooxanthellate soft corals. Mar. Ecol. Progr. Ser., 196, 157-167.

Farrow, D.E. and J.C. Patterson, 1993: On the response of a reservoir sidearm to diurnal heating and cooling. J. Fluid Mech., 246, 143-161

Frechette, M., C.A. Butman and W.R. Geyer, 1989: The importance of boundary-layer flows in supplying phytoplankton to the benthic suspension feeder, Mytilus edulis. Limnol. Oceanogr., 34, 19-36.

Gattuso, J.P., M. Frankignoulle, S.V. Smith, J.R. Ware and R. Wollast, 1996: Coral reefs and carbon dioxide. Science, 271, 1298-1298.

Glynn, P.W., 1973: Ecology of a caribbean reef. The Porites Reef-Flat Biotope: Part II. Plankton community with evidence for depletion. Mar. Biol., 22, 1-21.
Gross, T.F. and A.R. Nowell, 1983: Mean flow and turbulence scaling in a tidal boundary layer. Cont. Shelf Res., 2, 109-126.

Hata, H., A. Suzuki, T. Kurano, S. Miyachi, Y. Ikeda and H. Kayanne, 1998: Carbon flux by suspended and sinking particles around the barrier reef of Palau, western Pacific. Limnol. Oceanogr., 43, 1883-1893.

Hatcher, B.G., 1997: Organic production and decomposition. In: Life and Death of Coral Reefs. C. Birkeland, ed., Chapman \& Hall, 140-174.

Hearn, C.J., 1999: Wave-breaking hydrodynamics within coral reef systems and the effect of changing relative sea level. J. Geophys. Res. Oceans, 104, 30007-30019.

Hearn, C.J., M.J. Atkinson and J.L. Falter, 2001: A physical derivation of nutrient-uptake rates in coral reefs: effects of roughness and waves. Coral Reefs, 20, 347-356.

Hopkinson, C.S.J., R.D. Fallon, B.O. Jansson and J.P. Schubauer, 1991: Community metabolism and nutrient cycling Gray's Reef, a hard bottom habitat in the Georgia Bight. Mar. Ecol. Progr. Ser., 73, 105-120.

Kayanne, H., A. Suzuki and H. Saito, 1995: Diurnal changes in the partial-pressure of carbon-dioxide in coral-reef water. Science, 269, 214-216.

Korpal, T., 1991: Dissolved nutrients in the reef of the northern Gulf of Eilat-sources and fluxes. M.Sc. Thesis, The Hebrew University of Jerusalem (in Hebrew).

Monismith, S.G., J. Imberger and M.L. Morison, 1990: Convective motions in the sidearm of a small reservoir. Limnol. Oceanogr., 35, 1676-1702.

Odum, E.P., 1971: Fundamentals of Ecology. Sounders Co., Philadelphia.

O'Riordan, C.A., S.G. Monismith and J.R. Koseff, 1993: A study of concentration boundary-layer formation over a bed of model bivalves. Limnol. Oceanogr., 38, 1712-1729.

Reiss, Z. and L. Hottinger, 1984: The Gulf of Aqaba (Eilat) - ecological micropaleontology. Springer-Verlag, Berlin, $354 \mathrm{pp}$.

Richter, C., M. Wunsch, M. Rasheed, I. Kotter and M.I. Badran, 2001: Endoscopic exploration of Red Sea coral reefs reveals dense populations of cavity-dwelling sponges. Nature, 413, 726-730.

Street, R.L, G.Z. Watters and J.K. Vennard, 1996: Elementary Fluid Mechanics. Wiley, New York.

Thomas, F.I.M. and M.J. Atkinson, 1997: Ammonium uptake by coral reefs: Effects of water velocity and surface roughness on mass transfer. Limnol. Oceanogr., 42, 81-88.

Tribble, G.W., M.J. Atkinson, F.J. Sansone and S.V. Smith, 1994: Reef metabolism and endo-upwelling in perspective. Coral Reefs, 13, 199-201.

Wildish, D.J. and D. Kristmanson, 1997: Benthic Suspension Feeders and Flow. Cambridge Univ. Press., Cambridge, 409 pp.

Yahel, G., A.F. Post, K.E. Fabricius, D. Marie, D. Vaulot and A. Genin, 1998: Phytoplankton distribution and grazing near coral reefs. Limnol. Oceanogr., 43, 551-563. 